\title{
Laparoscopic Sterilization of the African Lioness (Panthera leo)
}

MARTHINUS HARTMAN, BVSc(Hons), ERIC MONNET, PhD, Diplomate ACVS, ECVS, ROBERT

KIRBERGER, MMedVet(Rad), Diplomate ECVDI, LEON VENTER, BVSc(Hons), LYNETTE BESTER, MMedVet(Anaes), MARTIN SCHULMAN, MMedVet (Gyn), TANIA SERFONTEIN, BSc, RETHA FOURIE, DipVetNur, JOHAN SCHOEMAN, PhD, Diplomate ECVIM

From the Department of Companion Animal Clinical Studies, Faculty of Veterinary Science, University of Pretoria, Private Bag X04, Onderstepoort 0110, Republic of South Africa

Supported by grants from Karl Storz Endoskope, the Department of Companion Animal Clinical Studies, Faculty of Veterinary Science, University of Pretoria, Pretoria, South Africa, the Arabella Dean fund of the South African Veterinary Foundation and Covidien.

Corresponding author: Marthinus J. Hartman, Section of Small Animal Surgery, Department of Companion Animal Clinical Studies, Faculty of Veterinary Science, University of Pretoria, Onderstepoort, 0110, South Africa. E-mail: marthinus.hartman@up.ac.za.

Objective: To describe laparoscopic ovariectomy and salpingectomy in the African lioness (Panthera leo) and to establish the technical elements and complications of the respective procedures.

Study Design: Descriptive study.

Animals: Female lions $(\mathrm{n}=16)$ 
Methods: Lionesses were randomly divided into two different procedure groups $\mathrm{O}$ (ovariectomy)(n=8) and S (salpingectomy)(n=8). Laparoscopic ovariectomy and salpingectomy were performed. Two different Veress needle placement techniques were used. Volumes of $\mathrm{CO}_{2}$ required for insufflation were recorded.

Results: Lionesses were immobilized using a combination of tiletamine and zolazepam or tiletamine and zolazepam and medetomidine. Intravenous propofol was given to effect to facilitate intubation and the patients maintained under isoflurane. Accurate descriptions of laparoscopic ovariectomy and salpingectomy in the African lioness resulted from this study. The poorly developed Mesosalpinx and ovarian bursa rendered the uterine tube more accessible for salpingectomy compared to that of the dog making the procedure easier in the lioness. Similarly salpingectomy is a relatively easier procedure compared to ovariectomy especially when the modified Hasson technique for Veress needle placement is used. Less CO2 was required in subadults than in adults.

Clinical Relevance: Laparoscopic ovariectomy and salpingectomy can be safely performed in the African lioness. Further studies are needed to determine the most effective surgical sterilization procedure to ensure a decrease in population numbers without disrupting the social patterns as well as the effects of different female sterilization techniques on the social behavior and pride structure of the African lion, particularly in free ranging lions.

Keywords: African lion, Panthera leo, laparoscopy, ovariectomy, salpingectomy 


\section{INTRODUCTION}

Currently there are an estimated four to five thousand African lions incorporated in breeding programs on commercial farms in South Africa. ${ }^{1}$ The need for population control in African lion prides on these farms has become a necessity. Male castration results in loss of the mane which is undesirable. Male vasectomy is a practical option but will result in mating without pregnancy. This may encourage lionesses to seek other "fertile" males and disrupt the social structure of the pride. Female sterilization therefore appears to be an option for lion population control worthy of investigation.

Induction of contraception in some African wild carnivores by down-regulation of $\mathrm{LH}$ and FSH secretion using the GnRH analogue deslorelin (Suprelorin ${ }^{\circledR}$ Virbac Pty Ltd, Halfway House, South Africa) is currently in use., ${ }^{2,3}$ However this requires lionesses to be immobilized and implanted every 12-24 months for maintenance of contraception. ${ }^{3}$ The practical implication of this is a cumulative cost and management effect, repeated stressful immobilizations and the lack of permanent sterilization.

Ovariectomy has proved to be a reliable method of sterilization ${ }^{4-6}$ and laparoscopic ovariectomy, ${ }^{7,8}$ ovariohysterectomy, ${ }^{9-11}$ uterine horn occlusion $^{12}$ and laparoscopic-assisted ovariohysterectomy ${ }^{13}$ have been widely applied to varying degrees in dogs. Laparoscopic ovariectomy has also been performed in cats using laser and bipolar electrocoagulation. ${ }^{14}$ In one study ovariohysterectomies were done in two hybrid Asian lions ${ }^{15}$ and in another study two laparoscopic ovariohysterectomies and three laparoscopic hysterectomies were performed in lions. ${ }^{16}$ Computer-controlled bipolar electrocoagulation has been extensively used in dogs ${ }^{17,18}$ 
and horses. ${ }^{19-21}$ The principles of laparoscopic technique, the application of laparoscopic equipment, the use of instrumentation and the placement of the Veress needle in canines and felines have been well described. ${ }^{22-24}$ Hasson described a technique for cannula placement that requires a bigger incision when compared to other methods of cannula placement for performing laparoscopic procedures. ${ }^{25,26}$

The primary author has conducted morphological ${ }^{27}$, computed tomographic ${ }^{28}$, angiographic and silicone $^{29}$ studies and has developed a sound anatomical knowledge around the splanchnology, topography and arterial supply ${ }^{30}$ that represents the anatomy of the female reproductive organs of the African lioness. The ovarian anatomy of the African lioness suggests that both laparoscopic ovariectomy and salpingectomy are possible. The purpose of this study was to describe laparoscopic ovariectomy and salpingectomy in the African lioness. We expected laparoscopic salpingectomy to be possible and that this procedure would be easier and quicker than ovariectomy.

\section{MATERIALS AND METHODS}

Sixteen lionesses from a commercial breeding farm were included in the study. The owner wanted to terminate his lion breeding program and therefore needed all his female lionesses sterilized. It was discussed with the owner to use two different surgical techniques as part of a surgical study which he consented to. The lionesses were between 8 months and 10 years of age. Lionesses would be excluded from the study if they had advanced pregnancy or uterine pathology diagnosed on ultrasound, were morbidly obese or had a body condition score of less 
than two. Lionesses were randomized into two procedure groups by using a randomization table: group O: ovariectomy or group S: salpingectomy. Two age groups were identified: adults over one year of age and sub-adults less than one year of age. The project was approved by the Animal Use and Care Committee and Research Committee of the Faculty of Veterinary Science, University of Pretoria (protocol number V051-10).

Anesthesia

Adult lionesses were fasted for approximately 24 hours and sub-adults for 12 hours but water was allowed ad lib. Lionesses were immobilized using a combination of tiletamine and zolazepam (Zoletil $^{\circledR,} 100 \mathrm{mg} / \mathrm{ml}$, Virbac, Halfway House, South Africa) $(\mathrm{n}=7)$ or tiletamine and zolazepam and medetomidine (Domitor ${ }^{\circledR,} 1 \mathrm{mg} / \mathrm{ml}$ Pfizer Animal Health, Sandton, South Africa) $(\mathrm{n}=9)$. The drug combinations were delivered by means of a DanInject ${ }^{\circledR}$ remote projection system using $3 \mathrm{ml}$ darts with $30 \mathrm{~mm}$ collared side-port needles (DanInject). Once the animal was suitably immobilized it was transported to the surgery facility. Intravenous propofol (Propofol $^{\mathbb{Q},} 10 \mathrm{mg} / \mathrm{ml}$, Fresenius-Kabi, Halfway House South Africa) was given to effect to facilitate intubation. Intravenous fluid $10 \mathrm{ml} / \mathrm{kg}$ /hour Ringer' Lactate (Intramed Ringer-Lactate Solution $^{\circledR}$, Fresenius-Kabi, Port Elizabeth, South Africa) was administered until extubation. Lions were connected to a semi-closed, rebreathing anesthetic circuit during preparation and maintained with a mechanical ventilator on a closed circuit on isoflurane gas (Isofor ${ }^{\circledR}$, Safeline Pharmaceuticals, Weltevredenpark, Roodepoort, South Africa). 
All the animals received a dose of $0.3 \mathrm{mg} / \mathrm{kg}$ of morphine (Morphine-Sulphate-Fresenius $\mathrm{PF}^{\circledR}$, $10 \mathrm{mg} / \mathrm{ml}$, Fresenius-Kabi, Port Elizabeth, South Africa) sub-cutaneously immediately after intubation and one $\mathrm{ml}$ of ropivacaine (Naropin $\AA, 7.5 \mathrm{mg} / \mathrm{ml}$, AstraZenaca Pharmaceuticals, Sunninghill Johannesburg, South Africa) sub-cutaneously at the sites of surgical incision.

After ultrasound examination the patient was placed in an endoscopic positioner (Apexx TT) in dorsal recumbency. Due to size of the patients their pelvic and thoracic parts were strapped to the positioner.

\section{Surgical preparation}

Lionesses were clipped and prepared for surgery with chlorhexidine gluconate as for a laparotomy. Sterile transparent plastic adhesive surgical drapes (Steridrape 1014, $320 \mathrm{~cm}$ x 214 cm, $48 \mathrm{~cm}$ x $25 \mathrm{~cm}, 3 \mathrm{M}$, Mexico, St. Paul) were used.

\section{Recovery}

Patients were weaned off the ventilator, transported back to the camps, extubated and allowed to recover in their night rooms under constant supervision of the anesthetic team. 
The lionesses were observed twice a day for two days by members of the surgical team and by the care taker. The patients were monitored for any abnormalities associated with appetite, habitus, wound dehiscence or hemorrhage.

\section{RESULTS}

Seventeen lionesses were considered of which one lioness was determined by ultrasound to be too far pregnant to safely undergo surgery. Two more lionesses were pregnant on ultrasound examination but surgery on these individuals was regarded to be safe.

A Veress needle was used for insufflation of the peritoneal cavity. The Veress needle was initially placed percutaneously with a small skin incision only. Difficulty was however experienced using this standard technique in the first seven lionesses. From lioness eight onwards a modified Hasson technique was adopted. For this technique, the skin incision was made 1.5 times the length of the marked diameter of the open ended tip of the $12 \mathrm{~mm}$ cannula. A cut down technique in the subcutaneous tissue was followed down to reach the linea alba. Two parallel horizontal stay sutures attached to Halstead's mosquito forceps were placed on either side of the linea alba, a $10 \mathrm{~mm}$ incision made in the linea alba and the Veress needle placed

through the incision. The abdominal cavity was insufflated with preheated $\mathrm{CO}_{2}$ to a pressure of $13 \mathrm{mmHg}$ with an automatic insufflator (Thermoflator, Karl Storz GMBH \& Co. KG, Tuttlingen, Germany). After insufflation, the Veress needle was removed and the $12 \mathrm{~mm}$ trocar and cannula were placed. The trocar was removed and the insufflator connection was repositioned to the cannula port and insufflation re-established. For both groups, the portals were positioned in a 
similar fashion. Three disposable trocar and cannula ports (cranial, center and caudal) were placed on the ventral midline. The center port (12 mm cannula) was placed first $3 \mathrm{~cm}$ caudal to the umbilical scar, the cranial port (10 $\mathrm{mm}$ cannula) $3 \mathrm{~cm}$ cranial to and the caudal port (10 $\mathrm{mm}$ cannula) $9 \mathrm{~cm}$ caudal to the umbilical scar respectively. One milliliter of ropivicaine was infused subcutaneously into all of the placement sites.

A $0^{\circ}$ laparoscope (HOPKINS Optik $0^{\circ}, 10 \mathrm{~mm}$, Karl Storz GMBH \& Co. KG, Tuttlingen, Germany) was inserted in the first port to visualize the peritoneal cavity. The spleen was briefly inspected and the cranial and caudal cannulas were placed under visualisation in order not to traumatize any visceral organs. The insufflator hose was repositioned to the cranial cannula port. The patients were first rotated $45^{\circ}$ to the left oblique and the relevant procedure completed on the right ovary. The patient was then rotated $45^{\circ}$ to the right oblique and the same procedure completed on the left ovary.

Group O: Ovariectomy. After placement of the laparoscope in the center cannula port the suspensory ligament was visualized. A $10 \mathrm{~mm}$ grasping forceps (Click Line BABCOCK Grasping Forceps, $10 \mathrm{~mm}, 45 \mathrm{~cm}$ Karl Storz GMBH \& Co. KG) was placed in the caudal port to grab the proper ligament. The ovary was moderately elevated, approximately half way to the abdominal wall, and a $10 \mathrm{~mm}$ vessel sealant device (Atlas, LigaSureTM ValleylabTM Covidien), 
Figure 1. Ovariectomy, coagulation of the ovarian artery and vein.

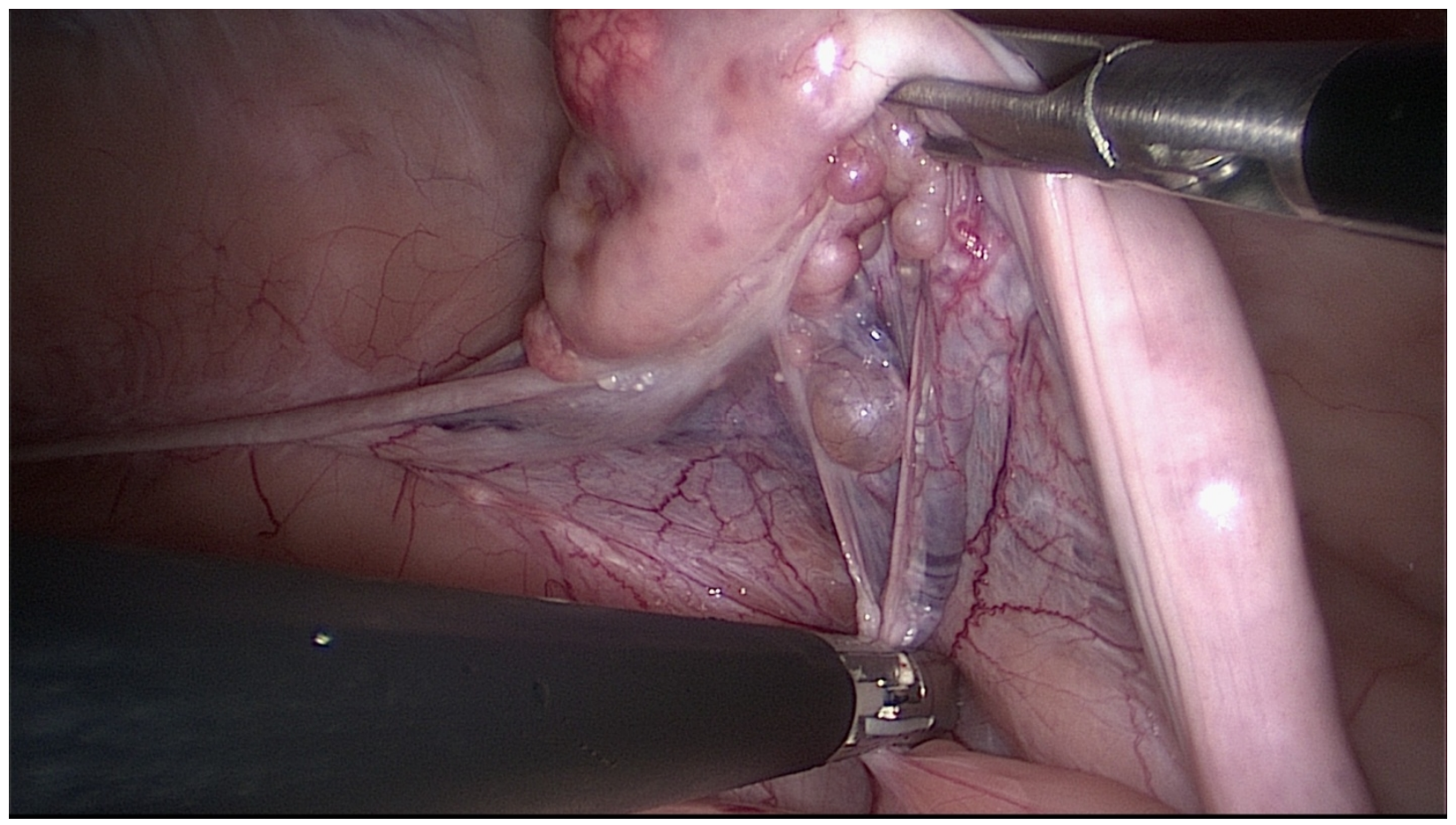

Figure 2. Ovariectomy, coagulation of the suspensory ligament.

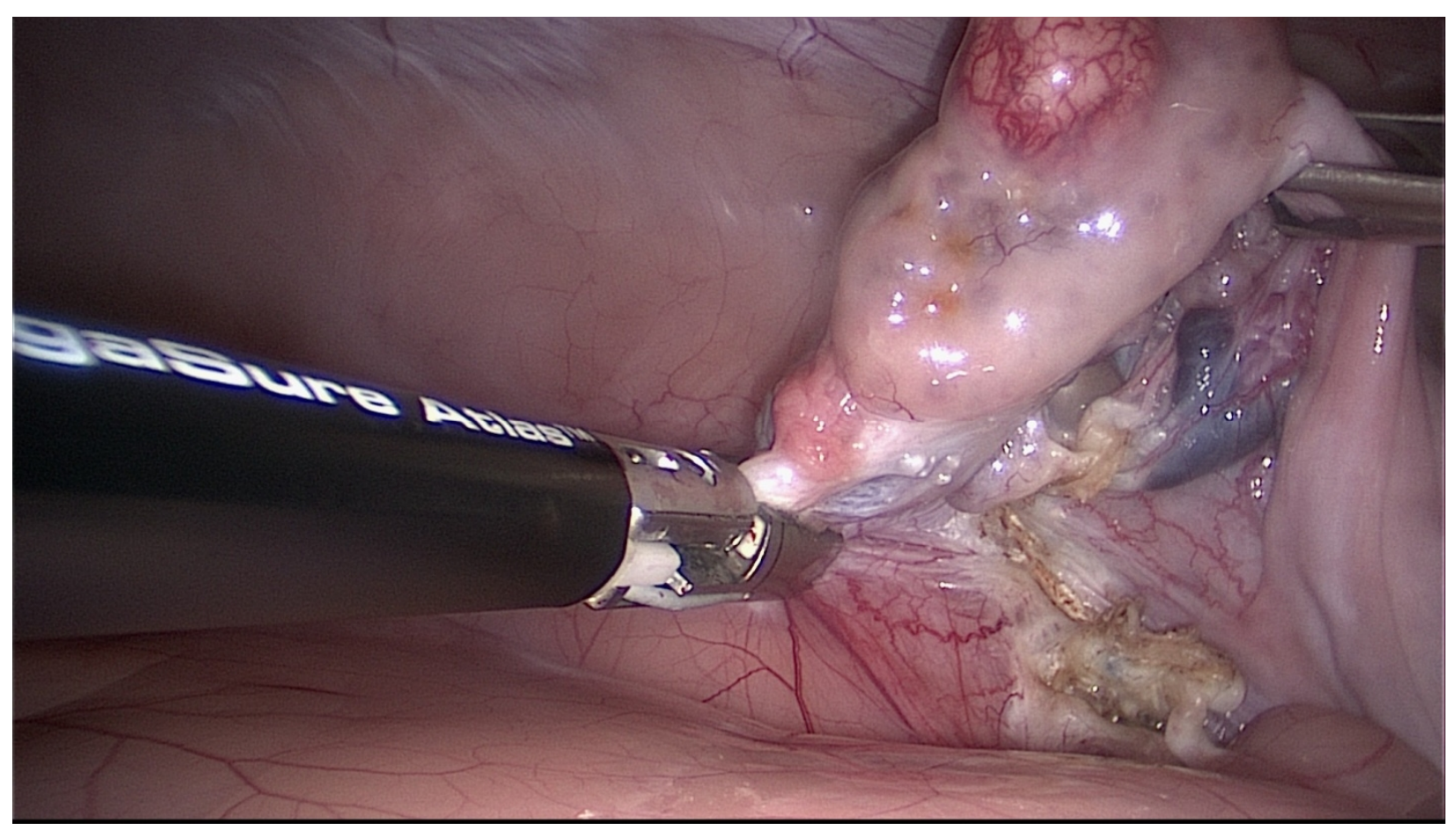


Figure 3. Ovariectomy, coagulation of the proper ligament.

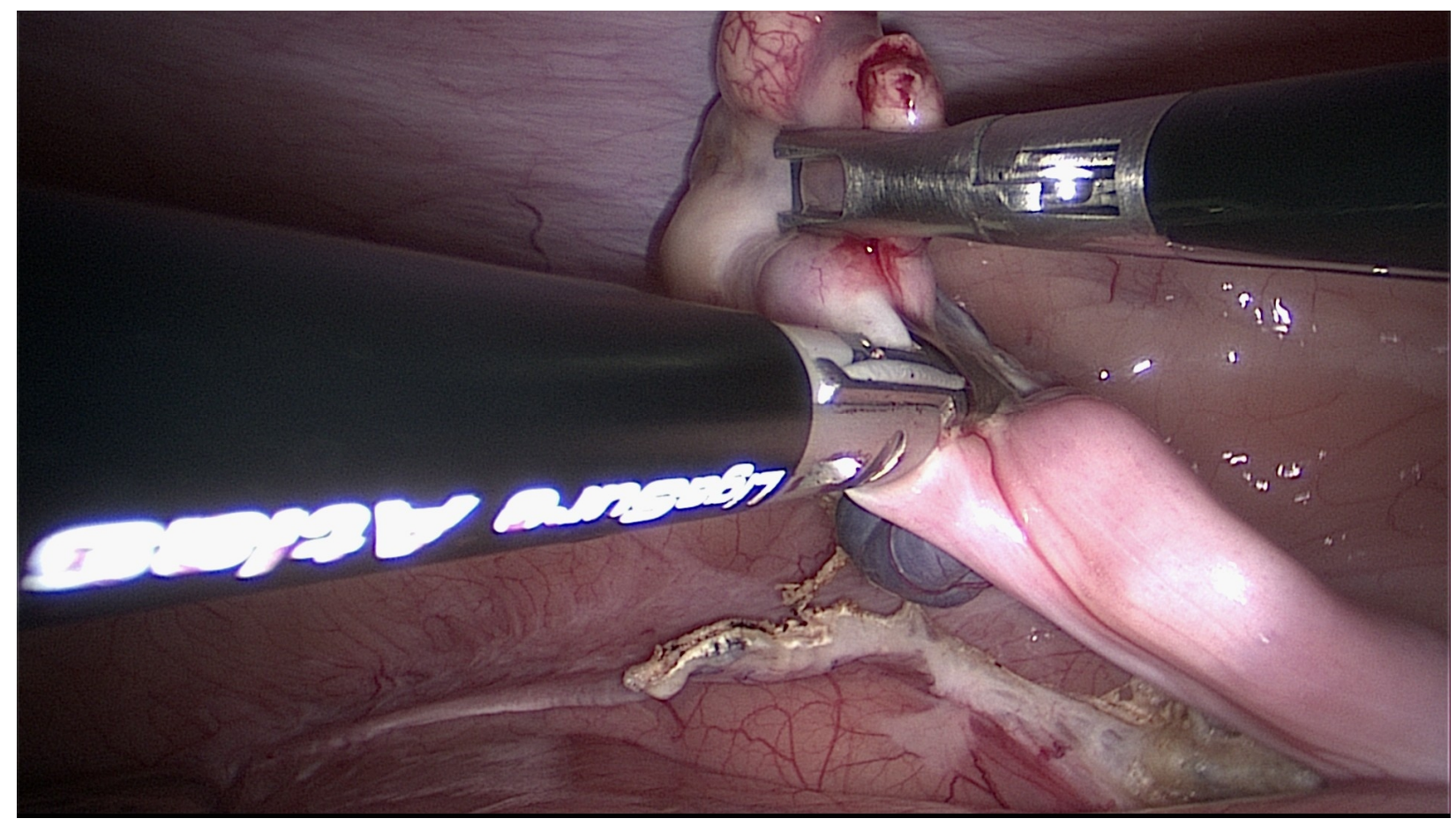

Figure 4. Ovariectomy, the ovary free from all attachments.

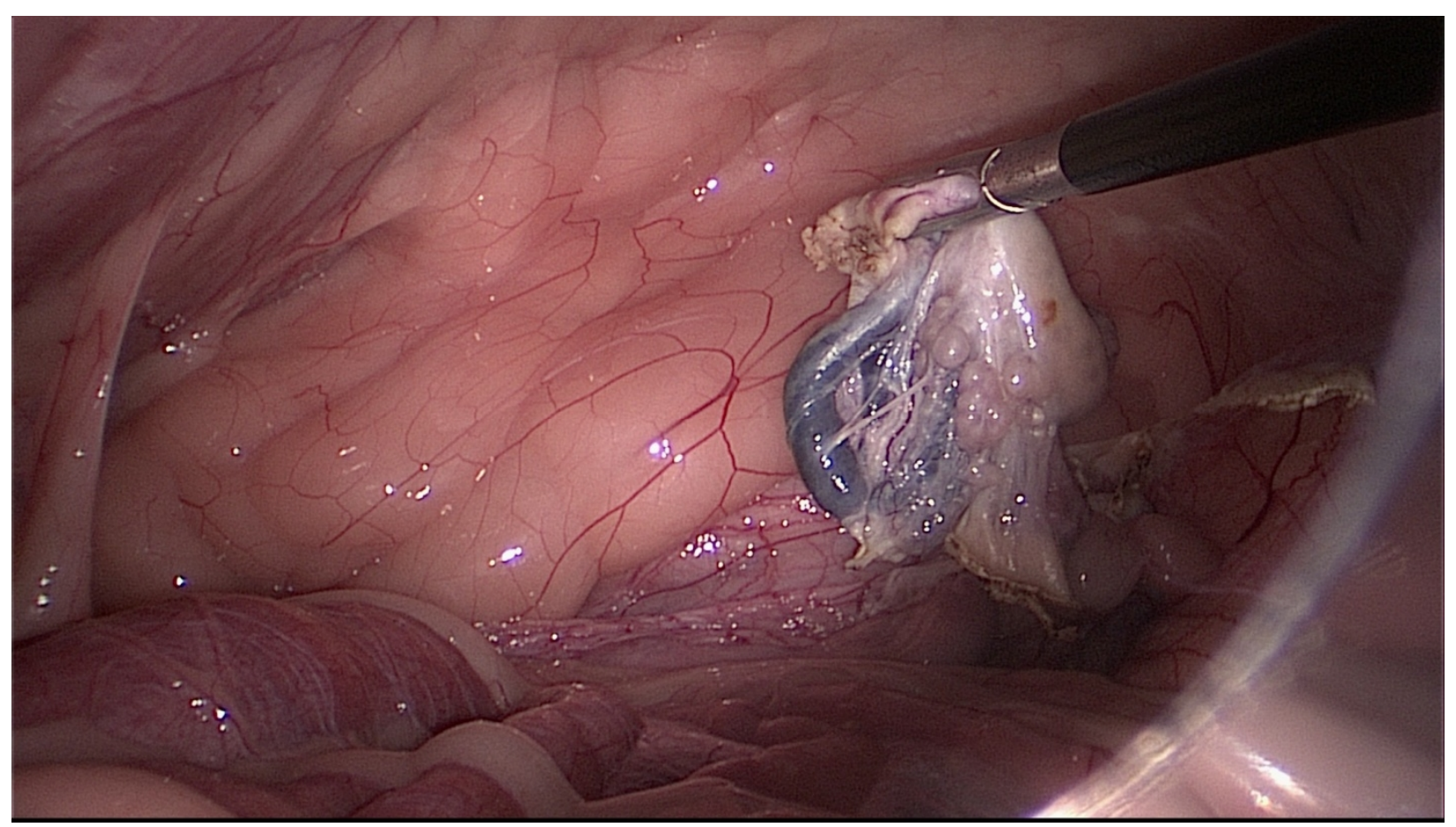


Figure 5. Salpingectomy, coagulation of the fimbriae and ascending part of the fallopian tube.

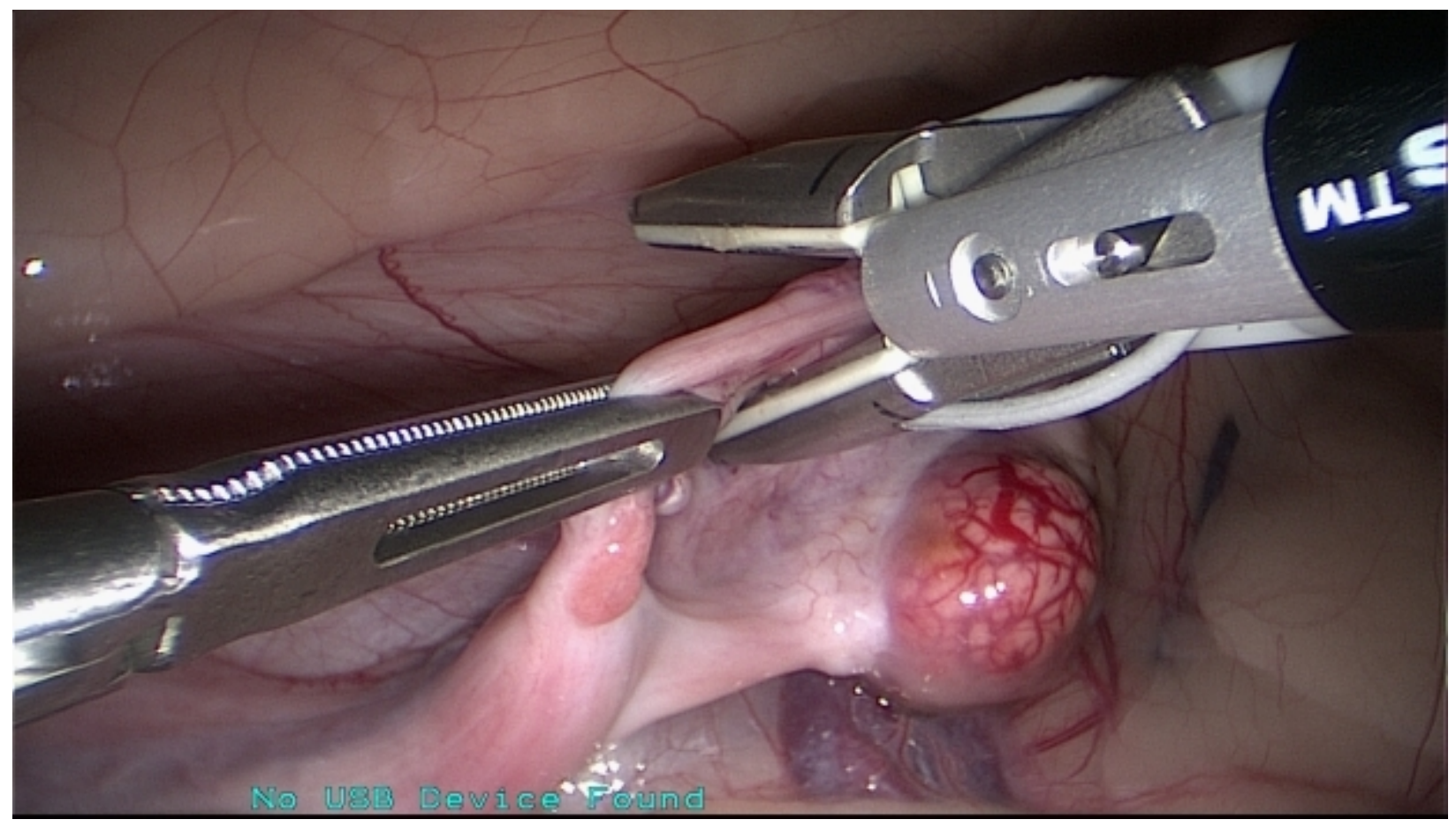

Figure 6. Salpingectomy, coagulation of the descending part of the fallopian tube and

Mesosalpinx.

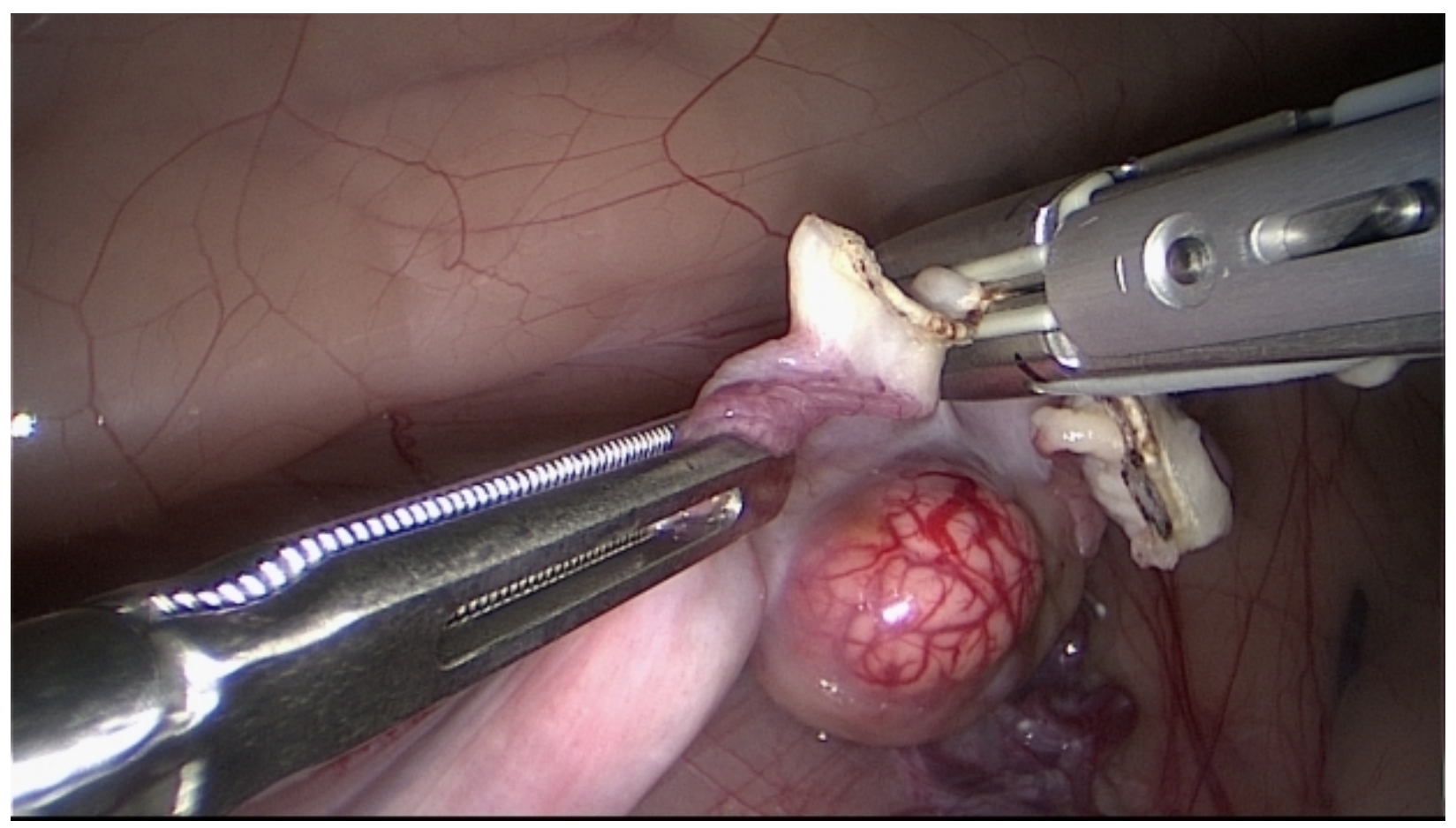


Figure 7. Salingectomy completed.

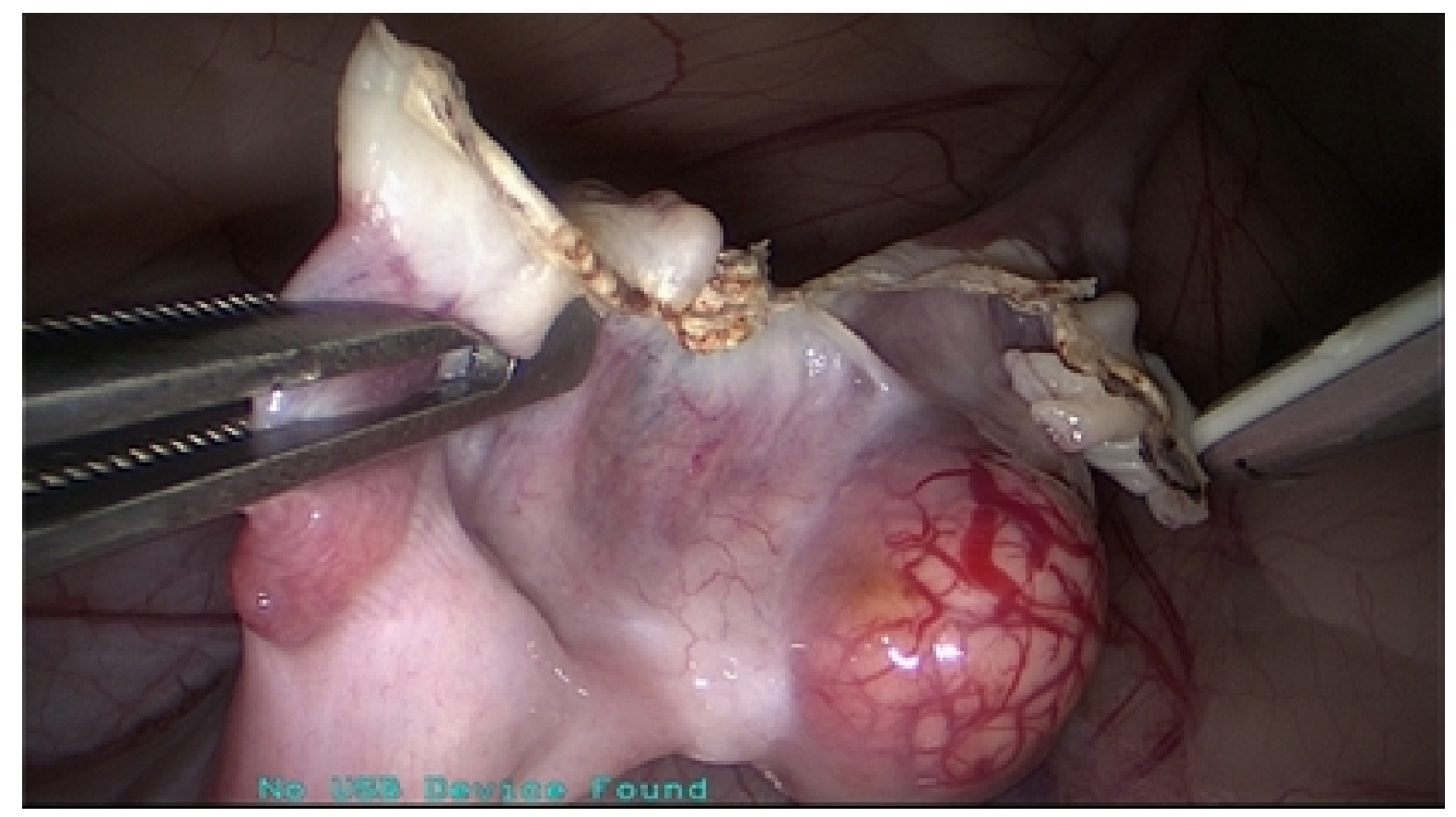

passed in the cranial port. The ovarian artery and vein were grasped, sealed and cut (Fig 1). A second bite was taken in the same area of the mesovarium to create a window. The suspensory ligament was sealed and cut (Fig 2) followed by the proper ligament (Fig 3), tip of the uterine horn and uterine artery to free the ovary from all its attachments (Fig 4). The tip of the uterine horn and mesovarial remnants were inspected for hemorrhage. The ovary was then removed through the center cannula port. The abdominal pressure was re-established to $13 \mathrm{~mm} \mathrm{Hg}$ when necessary especially in cases where the cannula had to be removed concurrently with the ovary. The contralateral ovary was removed. 
Group S: Salpingectomy. Similar to ovariectomy the laparoscope was placed in the center cannula port, the Babcock forceps in the caudal port and the $10 \mathrm{~mm}$ vessel sealant device in the cranial port. The first visible aspect of the ovary was the medial surface. The ovary was rotated medially with aid of the Babcock forceps in order to expose the uterine tube. The uterine tube was grasped with the Babcock forceps and elevated slightly. A $10 \mathrm{~mm}$ vessel sealant device was used to seal and cut the uterine tube and Mesosalpinx. Care was taken to coagulate and cut the ascending (Fig 5) and descending uterine tube and the entire width of the Mesosalpinx (Fig 6) up to the mesovarial margin of the ovary. The Mesosalpinx and severed ends of the uterine tube were observed for any signs of hemorrhage (Fig 7). The abdominal cavity was deflated and each port closed in a routine fashion.

Bodyweight, age and the volume of $\mathrm{CO} 2$ required to insufflate each patient's peritoneal cavity were recorded (Tables 1 and 2).

Table 1. Adult lionesses

\begin{tabular}{|c|c|c|c|c|c|c|}
\hline \multirow[t]{2}{*}{ Lioness } & \multicolumn{2}{|c|}{ Procedure } & \multicolumn{2}{|c|}{$\begin{array}{c}\text { Bodyweight } \\
\text { (kg) }\end{array}$} & \multicolumn{2}{|c|}{$\begin{array}{c}\text { Age } \\
\text { (years) }\end{array}$} \\
\hline & $\mathbf{O}$ & $\mathbf{S}$ & $\mathbf{O}$ & $\mathbf{S}$ & $\mathbf{O}$ & $\mathbf{S}$ \\
\hline 1 & $\mathrm{O}$ & & 160 & & 9 & \\
\hline 2 & & $\mathrm{~S}$ & & 100 & & 10 \\
\hline 3 (pregnant) & $\mathrm{O}$ & & 127 & & 3 & \\
\hline 4 & & $\mathrm{~S}$ & & 140 & & 9 \\
\hline far pregnant & - & - & - & - & - & - \\
\hline 5 (pregnant) & & $\mathrm{S}$ & & 136 & & 8 \\
\hline 6 & $\mathrm{O}$ & & 160 & & 9 & \\
\hline 7 & & S & & 141 & & 9 \\
\hline 8 & & $\mathrm{~S}$ & & 142 & & 10 \\
\hline 9 & $\mathrm{O}$ & & 133 & & 9 & \\
\hline 10 & $\mathrm{O}$ & & 128 & & 3 & \\
\hline 11 & & $\mathrm{~S}$ & & 143 & & 3 \\
\hline
\end{tabular}


Table 2. Sub-adult lionesses

\begin{tabular}{|c|c|c|c|c|c|c|}
\hline \multirow[t]{2}{*}{ Lioness } & \multicolumn{2}{|c|}{ Procedure } & \multicolumn{2}{|c|}{$\begin{array}{l}\text { Bodyweight } \\
\text { (kg) }\end{array}$} & \multicolumn{2}{|c|}{$\begin{array}{c}\text { Age } \\
\text { (months) }\end{array}$} \\
\hline & $\mathbf{O}$ & $\mathbf{S}$ & $\mathbf{O}$ & $\mathbf{S}$ & $\mathbf{O}$ & $\mathbf{S}$ \\
\hline 1 & $\mathrm{O}$ & & 42 & & 8 & \\
\hline 2 & & $\mathrm{~S}$ & & 45 & & 8 \\
\hline 3 & & $\mathrm{~S}$ & & 42 & & 8 \\
\hline 4 & $\mathrm{O}$ & & 40 & & 8 & \\
\hline 5 & $\mathrm{O}$ & & 39 & & 8 & \\
\hline
\end{tabular}

Intraoperative complications

These included one ovary that slipped off the grasping forceps during retrieval through the body wall. It was however located by reestablishing the cannula and laparoscopic visualization where it was situated within the layers of the body wall. The ovary was re-grasped and successfully retrieved. Another ovary was dropped during manipulation and it too was successfully located and removed.

Postoperative complications

All lionesses returned to normal behavior within 24 hours of surgery. One lioness demonstrated mild pelvic limb weight bearing lameness for two days, most likely due to neuropraxia caused by positioning. The lameness progressively improved over the two days and she was clinically sound on day three. Her habitus and appetite however remained normal during the entire postoperative period. 


\section{DISCUSSION}

Laparoscopic ovariectomy and salpingectomy can be safely performed in the African lion. Factors that influenced surgery were prominent subcutaneous fat, intra-abdominal fat depositions in the median and falciform ligaments and the removal of ovaries in the adults. There was almost no fat present in the ovarian pedicle in contrast to prominent fat deposits in the median and falciform ligaments and subcutaneously. It therefore did not vary markedly between individuals as it does in $\operatorname{dog} s^{35}$. In some individuals where the uterine horn was larger in diameter, sealing of the proper ligament and tip of the horn was more time consuming. Surgery was easier in sub-adults because they had less body fat than adult lionesses and their ovaries were smaller.

In the first seven lionesses Veress needle placement was performed with a standard technique $^{22}$ by making a skin incision similar to the size of the cannula's open ended tip. The Veress needle was blindly placed through the abdominal wall and insufflation started. However, difficulty was experienced using this technique due to very thick subcutaneous fat ${ }^{32}$ and very prominent fat in the median ligament of the bladder especially in one lioness. A very strong linea alba and abdominal musculature contributed to this obstacle and also complicated placement of the trocar and cannula. For subsequent patients a modified Hasson technique ${ }^{26}$ was adopted for placement of the Veress needle and cannula port.

In the first few patients a $10 \mathrm{~mm}$ cannula was placed in the centre port, a $12 \mathrm{~mm}$ cannula in the cranial port and $10 \mathrm{~mm}$ cannula in the caudal port. It was discovered that retrieving the ovaries via the cranial $(12 \mathrm{~mm})$ port was difficult due to the presence of prominent falciform fat in this 
area cranial to the umbilicus. For subsequent patients the $10 \mathrm{~mm}$ cannula was exchanged for the $12 \mathrm{~mm}$ cannula in the centre port (caudal to the umbilicus) for retrieval of the ovaries in an area where less abdominal fat was present. This also necessitated exchanging the grasping forceps and laparoscope between these ports. The laparoscope was moved to the cranial port and the grasping forceps to the centre port. In all of the lionesses access to the ovaries was comfortably achieved with $36 \mathrm{~cm}$ instruments. In all of the sub-adult patients the ovaries were small enough to comfortably be retrieved through the $12 \mathrm{~mm}$ cannula lumen compared to adult lionesses where the cannula had to be removed concurrently in most patients. However it was not necessary to increase the cannula incision even in adult lionesses.

Various advances have been made in laparoscopy in reducing the number of ports in both human $^{33-39}$ and veterinary surgery. ${ }^{8-10,13,40,41}$ The use of an ovariectomy hook or transabdominal suture contribute to reducing the number of portals used in sterilisation ${ }^{13,40}$ and other procedures. $^{42,43}$ The well-developed abdominal musculature of the lion precluded the use of these aids and resulted in the use of three ports during both procedures. Single-incision laparoscopic surgery (SILS) ${ }^{44}$ should be considered in future as an alternative approach for ovariectomy and salpingectomy in the African lion in an attempt to reduce the amount of soft tissue trauma and possibly reduce surgery times.

To improve visualization of and access to the ovaries different positioning options exist. Neither the Trendelenburg position ${ }^{8,9,11,17}$ or true lateral position ${ }^{41}$ were required in our patients. A $45^{\circ}$ lateral oblique tilt of the mechanical positioner was sufficient to visualize the ovaries, despite some manipulation of the spleen being necessary to allow access to the left ovary. However, a lateral tilt of $15-30^{\circ}$ as suggested by some authors ${ }^{13,18}$ would probably not have been adequate in patients of this size. 
A $10 \mathrm{~mm}$ vessel sealant device was used during the procedure. The device had to be applied several times across the proper ligament and tip of the uterine horn, to complete soft tissue dissection, especially in adults. During salpingectomy the device had to be applied once only for each transection of the salpinx and mesosalpinx respectively. Laceration of the spleen was not observed in any of the patients. It is possible that positioning on the endoscopic positioner could have caused transient lameness in one lioness. Follow up was limited to visual inspection of the animals in their natural habitat.

We found that laparoscopic ovariectomy and salpingectomy could safely and successfully be performed in the African lioness. The poorly developed Mesosalpinx and ovarian bursa renders the uterine tube more accessible for salpingectomy compared to that of the dog making the procedure easier in the lioness. Similarly salpingectomy is a relatively easier procedure compared to ovariectomy especially when the modified Hasson technique for Veress needle placement is used. Less $\mathrm{CO}_{2}$ was required in sub-adults than in adults.

Under field conditions where a controlled theatre environment might not be practical both procedures should be faster in sub-adults and performing salpingectomy in adults should be faster than ovariectomy. Laparoscopic ovariectomy and salpingectomy are surgical options with future application for population control in South African lion prides. These procedures and their possible complications therefore had to be described prior to wider scale implementation. The time constraints of performing surgery on wild carnivores under field conditions and transportation of heavy and space occupying $\mathrm{CO}_{2}$ bottles are logistical considerations to these procedures. Further studies are needed to determine the most effective surgical sterilization procedure to ensure a decrease in population numbers without disrupting the social patterns as 
well as the effects of different female sterilization techniques on the social behavior and pride structure of the African lion, particularly in free ranging lions.

\section{ACKNOWLEDGEMENTS}

The authors thank Karl Storz for supplying and managing all the laparoscopic equipment and the instrumentation, Covidien for supplying LigaSure hand pieces, Health and Hygiene for supplying F10 products, Virbac for supplying Zoletil and Scientific Group for supplying anesthetic equipment. The authors also thank the Department of Companion Animal Clinical Studies, Faculty of Veterinary Science, University of Pretoria, Pretoria, South Africa and the Arabella Dean fund of the South African Veterinary Foundation for funding. This study was partly funded by the NRF grant of Prof. Schoeman.

\section{REFERENCES}

1. South African Predators Breeder Association. Numbers of Lions in South Africa, 2009. Personal communication

2. Bertschinger HJ, Guimaraes MA, Trigg TE, et al: The use of deslorelin implants for the long-term contraception of lionesses and tigers. Wildlife Res 35:525-530, 2008 
3. Bertschinger HJ, Trigg TE, Jochle W: 2002 Induction of contraception in some African wild carnivores by downregulation of LH and FSH secretion using the GnRH analogue deslorelin. In: Proceedings of the fifth international symposium on fertility control in wildlife, held at Skukuza, The Kruger National Park, South Africa. 41-52, August 2001

4. Okkens AC, Kooistra HS, Nickel RF: Comparison of long-term effects of ovariectomy versus ovariohysterectomy in bitches. Prakt Tierarzt 84:98-101, 2003

5. Howe LM: Surgical methods of contraception and sterilization. Theriogenology 66:500509,2006

6. van Goethem B, Schaefers-Okkens A, Kirpensteijn J: Making a rational choice between ovariectomy and ovariohysterectomy in the dog: a discussion of the benefits of either technique. Vet Surg 35:136-143, 2006

7. Nudelmann N: La laparoscopie chez les carnivores domestiques. Actes chirurgicaux d'abord unique. Rec Méd Vét 172:643-652, 1996

8. van Goethem B, Rosenveldt KW, Kirpensteijn J: Monopolar vs. bipolar electrocoagulation in canine laparoscopic ovariectomy: a nonrandomized, prospective, clinical trial. Vet Surg 32:464-470, 2003

9. Austin B, Lanz OI, Hamilton SM, et al: Laparoscopic ovariohysterectomy in nine dogs. J Am Anim Hosp Assoc 39:391-396, 2003 
10. Davidson EB, Moll HD, Payton ME: Comparison of laparoscopic ovariohysterectomy and ovariohysterectomy in dogs. Vet Surg 33:62-69, 2004

11. Hancock RB, Lanz OI, Waldron DR, et al: Comparison of postoperative pain after ovariohysterectomy by harmonic scalpel-assisted laparoscopy compared with median celiotomy and ligation in dogs. Vet Surg 34:273-282, 2005

12. Wildt DE, Lawler DF: Laparoscopic sterilization of the bitch and queen by uterine horn occlusion. Am J Vet Res 46:864-869, 1985

13. Devitt CM, Cox RE, Hailey JJ: Duration, complications, stress, and pain of open ovariohysterectomy versus a simple method of laparoscopic-assisted ovariohysterectomy in dogs. J Am Vet Med Assoc 227:921-927, 2005

14. van Nimwegen SA, Kirpensteijn J: Laparoscopic ovariectomy in cats: comparison of laser and bipolar electrocoagulation. J Feline Med Surg 9:397-403, 2007

15. Aguilar RF, Mikota SK, Smith J, et al: Endoscopic ovariohysterectomy in two lions (Panthera leo). J Zoo Wildlife Med 28:290-297, 1997

16. Kolata R: Laparoscopic ovariohysterectomy and hysterectomy on African lions (Panthera leo) using the UltraCision(R) Harmonic Scalpel(R). J Zoo Wildlife Med 33:280282,2002

17. Wenkel R, Ziemann U, Thielebein J, et al: Laparoscopic castration of the bitch presentation of new procedures for the minimally invasive ovariohysterectomy. Tieraerztl Prax K H 33:177-188, 2005 
18. Mayhew PD, Brown DC: Comparison of three techniques for ovarian pedicle hemostasis during laparoscopic-assisted ovariohysterectomy. Vet Surg 36:541-547, 2007

19. Hand R, Rakestraw P, Taylor T: Evaluation of a vessel-sealing device for use in laparoscopic ovariectomy in mares. Vet Surg 31:240-244, 2002

20. Rumbaugh ML, Burba DJ, Natalini C, et al: Evaluation of vessel-sealing device for small intestinal resection and anastomosis in normal horses. Vet Surg 32:574-579, 2003

21. Hendrickson D: Laparoscopic cryptorchidectomy and ovariectomy in horses. Vet Clin N Am-Equine 22:777-798, 2006

22. Monnet E, Twedt DC: Laparoscopy. Vet Clin Small Anim 33:1147-1163, 2003

23. Monnet E: Minimally invasive surgery. Austr Small Anim Vet Assoc 605-606, 2008

24. Monnet E, Lhermette P, Sobel D: Rigid endoscopy: laparoscopy, in Lhermette P, Sobel D : BSAVA manual of canine and feline endoscopy and endosurgery. Gloucester, British Small Anim Vet Assoc pp 158-174, 2008

25. Hasson: A modified instrument and method for laparoscopy. Am J Obstet Gynecol $110: 886-887,1971$

26. Hasson: Open laparoscopy. Biomed Bull 5:1-6, 1984

27. Hartman MJ, Groenewald HB, Kirberger RM: Morphology of the reproductive organs of the African lioness (Panthera leo). Personal communication 
28. Hartman MJ, Kirberger RM: Computed tomographic and laparoscopic anatomy of the reproductive organs of the African lioness (Panthera leo). Personal communication

29. Hartman MJ, Groenewald HB: Silicone cast in situ: A technique to study the arterial supply of the female reproductive organs of the African lion (Panthera leo). Personal communication

30. Hartman MJ, Groenewald HB: Arterial supply of the reproductive organs of the African lioness (Panthera leo). Personal communication

31. van Nimwegen SA, Kirpensteijn J: Comparison of Nd:YAG surgical laser and Remorgida bipolar electrosurgery forceps for canine laparoscopic ovariectomy. Vet Surg $36: 533-540,2007$

32. Kirberger RM, Schulmann ML, Hartman MJ: Ultrasonographic and laparoscopic evaluation of the reproductive tract of the captive female African lion (Panthera leo). Theriogenology 76:810-818, 2011

33. Leggett PL, Churchman-Winn R, Miller G: Minimizing ports to improve laparoscopic cholecystectomy. Surg Endosc 14:32-36, 2000

34. Ghezzi F, Raio L, Mueller MD, et al: Two-trocar adnexal surgery a "quasi" scarless operation. Surg Endosc 18:825-828, 2004

35. Ates O, Hakguder G, Olguner M, et al: Single-port laparoscopic appendectomy conducted intracorporeally with the aid of a transabdominal sling suture. J Pediatr Surg 42:1071-1074, 2007 
36. Vix M, Solano C, Asakuma M, et al: One trocar sleeve gastrectomy using the air-sealed port in a porcine model. WeB-Surg.com 8:1, 2008

37. Desai MM, Rao PP, Aron M, et al: Scarless single port transumbilical nephrectomy and pyeloplasty: first clinical report. BJU Int 101:83-88, 2008

38. Ghezzi F, Cromi A, Fasola M, et al: One-trocar salpingectomy for the treatment of tubal pregnancy: a "marionette-like" technique. BJOG 112:1417-1419, 2005

39. Valla J, Ordorica-Flores RM, Steyaert H, et al: Umbilical one-puncture laparoscopicassisted appendectomy in children. Surg Endosc 13:83-85, 1999

40. Tankerseley T: Laparoscopic spay in dogs and cats [DVD]. Tuttlingen, Germany, Karl Sotrz GMBH \& Co KG, 2006

41. Dupré G, Fiorbianco V, Skalicky M, et al: Laparoscopic ovariectomy in dogs: comparison between single portal and two-portal access. Vet Surg 38:818-833, 2009

42. Rosin D, Kuriansky J, Rosenthal RJ, et al: Laparoscopic transabdominal suspension sutures. Surg Endosc 15:761-763, 2001

43. Navarra G, Ascanelli S, Sortini D, et al: Laparoscopic transabdominal suspension sutures. Surg Endosc 16:1378-1379, 2002

44. Froghi F, Sodergren MH, Darzi A, et al: Single-incision laparoscopic surgery (SILS) in general surgery: a review of current practice. Surg Laparosc Endosc Percutan Tech $20: 191-204,2010$ 